\title{
Congenital Diaphragmatic Hernia with Delayed Diagnosis: Report of Two Cases
}

\author{
Sidney Pereira Pinto Lemos ${ }^{1}$, Patrícia Veruska Ribeiro Barbosa Lemos ${ }^{2}$, \\ Natália Araújo Lima Rocha Coelho ${ }^{3}$, Danielle Moreira de Abrêu ${ }^{3}$, \\ Lucas Barbosa Ribeiro Feitosa ${ }^{4}$ \\ ${ }^{1}$ Pediatric Surgery, Integrative Medicine Institute, Fernando Figueira/College of Medicine, Universidade Federal \\ do Vale do São Francisco. UNIVASF Campus Petrolina. Av. Joséde SáManiçoba, S/NCenter, Petrolina, \\ Brasil \\ ${ }^{2}$ Gynecology and Obstetrics, College of Medicine, Universidade Federal do Vale do São Francisco (UNIVASF), \\ Petrolina, Brasil \\ ${ }^{3}$ Universidade Federal do Vale do São Francisco (UNIVASF), Petrolina, Brasil \\ ${ }^{4}$ Universidade Federal de Pernambuco, Recife, Brasil \\ Email: sppls@hotmail.com
}

Received 7 March 2015; accepted 21 March 2015; published 25 March 2015

Copyright (C) 2015 by authors and Scientific Research Publishing Inc.

This work is licensed under the Creative Commons Attribution International License (CC BY). http://creativecommons.org/licenses/by/4.0/

(c) (i) Open Access

\section{Abstract}

Introduction: Advances in prenatal imaging studies have allowed early diagnosis of Congenital Diaphragmatic Hernia (CDH), although neonatal mortality remains at high levels (60\% survival). Despite advances, this study found delayed diagnosis, demonstrating subdiagnosis, possibly caused by lack of resources and/or prenatal diagnostic failure. Case Report 1: Infant, 4 months and 22 days old, dyspneic, cyanotic, with fever and vomiting for 3 days, treated as pneumonia. After the second chest radiography, a right $\mathrm{CDH}$ was revealed. Surgical correction was performed and removal of Meckel's diverticulum was surgical findings. The patient was discharged on the 10th days after admission. Case Report 2: Infant, 11 months and 3 days old, distended abdomen, with fever and dyspnea for 2 days, treated as pneumonia. After the second chest radiography, a left CDH was revealed. The patient was submitted to surgery, intestinal loop incarceration without necrosis was observed, and the correction of CDH was performed. The patient was discharged on the 7th day after admission. Discussion: Three cases, between July 2012 and July 2013, were diagnosed at Dom Malam Hospital; 2 Cases of $\mathrm{CDH}$, with delayed diagnosis, showed incidence of 66.66\%. Delayed diagnosis of these patients with initial hypotheses of pneumonia demonstrated high risk, emphasizing the importance of diagnosis research through observation of the clinical course, the correct imaging interpretation, in order to establish early diagnosis and treatment. 


\section{Keywords}

\section{Diaphragmatic Hernia, Diaphragm, Bochdalek}

\section{Introduction}

Congenital Diaphragmatic Hernia $(\mathrm{CDH})$ consists of a defect in the diaphragm embryonic formation, due to the not closure of pleura peritoneal channels, resulting in a large opening (foramen of Bochdalek) in the posterolateral region of the diaphragm which makes the peritoneal and pleural cavities continuous.

Advances in prenatal imaging studies have allowed earlier diagnosis and improved estimates of the severity and prognosis before birth, according to lung volume assessment criteria, with diagnostic reference by ultrasound in the 15th week of gestation [1]. In addition, a better understanding of the pathophysiology and the development of new therapies have led to advances in the early treatment of HDC in pediatric intensive care units $[1]$.

The CDH affects approximately 1 in every 2000 - 5000 live births [2] [3] and it is a major cause of neonatal mortality and morbidity, and despite the advances in therapeutic, such as high frequency ventilation, nitric oxide and extracorporeal membrane oxygenation (ECMO), and improvement in surgical management of $\mathrm{CDH}$, the rate of mortality remains high [4].

According to the Extracorporeal Life Support Organization Registry, the median survival estimate of children with $\mathrm{CDH}$ is around $60 \%$ [4], being one of the main determinants of mortality in $\mathrm{CDH}$, which include coexistence of the major anomalies (complex $\mathrm{CDH}$ ), the diaphragm defect size, the degree of pulmonary hypoplasia, the severity of pulmonary hypertension in the perinatal period and the side of the hernia defect [5] [6].

Some morbidities are commonly found associated with $\mathrm{CDH}$, such as pulmonary hypertension, gastrointestinal dysfunction, sequels in neurodevelopment and hearing deficiency, among others [7].

The spectrum of the disease can range from asymptomatic defects, not diagnosed in the neonatal period, which appear later, to presentations with immediate respiratory failure, resulting in neonatal death [5].

Despite the advanced diagnostic and therapeutic resources available, this study found that patients with delayed diagnosis, which showed the existence of subdiagnosis, were possibly caused by lack of resources in some hospitals and failure in prenatal diagnosis.

The objective of this study was to analyze the evolution and prognosis of two cases of Congenital Diaphragmatic Hernia, delayed diagnoses in Dom Malan Hospital during the period.

\section{Description}

At Dom Malan Hospital in Petrolina, Pernambuco, Brazil, in the period between July 2012 and July 2013, two cases of patients with delayed diagnosis of Congenital Diaphragmatic Herniawere observed.

The study included just those cases whose diagnosis was made after 28 days, in other words, after the neonatal period; and the data for patients who had their diagnoses in the prenatal period or during the first 28 days after birth being excluded.

Clinical Case 1:

Male patient admitted to the service at 4 months and 22 days old, weighing $5.6 \mathrm{~kg}$ with a history of dyspnea and acute diarrhea for about 3 days, associated with recurrent episodes of cyanosis, sweating, cold skin, fever and vomiting, with no history of previous similar episodes or previous hospitalizations.

Physical examination showed tachydyspneic with a respiratory rate of $72 \mathrm{ipm}$, cyanotic, with subcostal retraction, vesicular murmur at base of the right hemithorax (RHT) and crackling in the left hemithorax base (LHT), mottled skin, tachycardia with heart rate $150 \mathrm{bpm}$, presence of heart murmur.

The hemogram showed: hemoglobin (Hbg): 9.1; hematocrit (Hct): 27.7; mean corpuscular volume (MCV): 80.1; mean corpuscular hemoglobin $(\mathrm{MCH}): 26.3$; red blood cell distribution width (RDW): 12.8; WBC: 7400; lymphocytes: $88.4 \%$; monocytes: $8.6 \%$; eosinophil: $0.8 \%$; platelets: 38,000 .

Pneumonia and right pleural effusion were hypothesized and antibiotic therapy with ceftriaxone and oxacillinwas started, without significant clinical improvement after 48 hours.

Chest radiogram was performed, and a suggestive image of bowel loops in the right hemithorax was showed (Figure 1). 


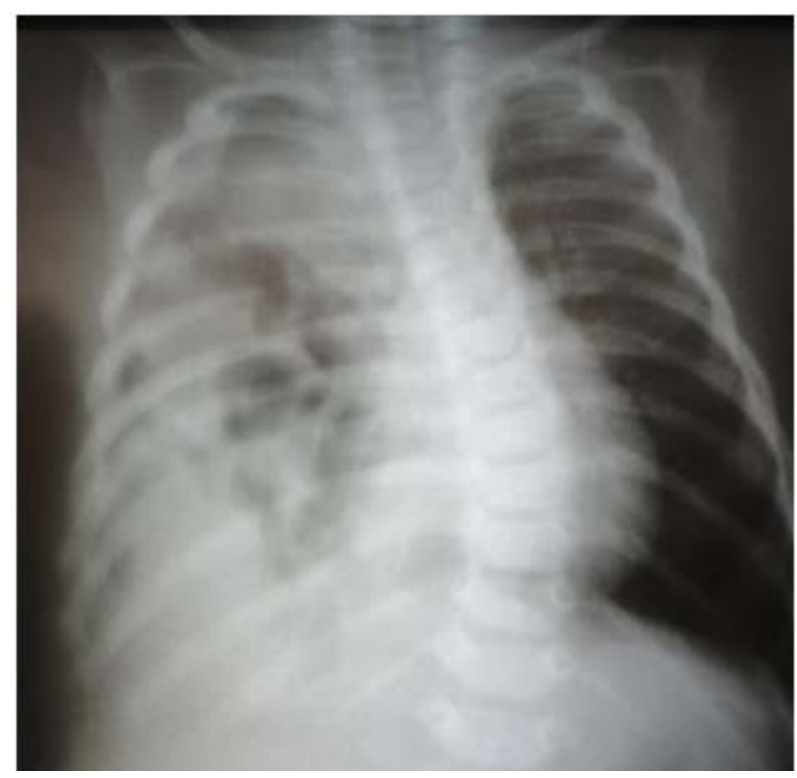

Figure 1. Chest X-ray showing bowel in RHT.

Surgical repair of diaphragmatic hernia posterolateral right was performed and the presence of Meckel's diverticulum was observed during surgery, and the diverticulectomy was simultaneously carried out.

The patient remained in the intensive care unit (ICU) for a period of 2 days after surgery, on mechanical ventilation via endotracheal tube, and red blood cells were infused 1 unit and 1 unit of platelet concentrate.

The patient was extubated the next day and oxygen support was started by Venturi mask at $50 \%$.

Major improvement of the respiratory condition was observed, and spontaneous breathing was carried out in the same day, with adequate saturation in room air. The patient was discharged from the ICU to the pediatric ward.

Oral dietwas started on the third postoperative day (POD), in the pediatric ward, with good acceptance. On the 6th POD, chest tube on the right was removed.

The patientwas discharged after 10 days of hospitalization in a good general state and spontaneous ventilation.

Clinical Case 2:

Female patient, 11 months and 3 days old, weighing $5.6 \mathrm{~kg}$, with history of abdominal distention, fever and dyspnea for two days without reporting admissions or similar previous episodes.

Physical examination showed bad general status, tachydyspneic, with a respiratory rate of 52 breath saminute, fever $\left(38.5^{\circ} \mathrm{C}\right)$, pale $(+/ 4+)$, cyanosis, jaundice, dehydrated $(+/ 4+)$, underactive.

The patient presented "crackles" in the left hemithorax (THE) in respiratory auscultation, intercostal retractions present. Without changes in cardiac auscultation, distended abdomen, depressible, painful to superficial palpation, with hyperactive RHA.

The hemogram showed: Hbg: 11.8; Hct: 36; MCV: 82.9; MCH: 27.2; RDW: 13.8; WBC: 11200; metamelocytes: $4 \%$; band neutrophils: $17 \%$; segmented neutrophils: $36 \%$; Lymphocytes: $32 \%$; Monocytes: $10 \%$; Eosinophil: $1 \%$; Platelets: 428,000 .

Diagnosis of pneumonia was suggested, and the antibiotic therapy with ampicillin and gentamicin was started.

Radiography of thoracoabdominal was performed (Figure 2), which showed the presence of intestinal loop and stomach in the left lung field.

The patient was submitted to exploratory laparotomy, with diaphragmatic hernia posterolateral left with imprisonment of intestinal ileal loops as the surgical findings, showing signs of vascular stress and the presence of the spleen and stomach in the left hemithorax.

The reduction of the content to the abdomen was performed, with improvement in perfusion of the bowel, with no need for resection, and the surgical repair of diaphragmatic hernia was carried out.

The patient remained in the hospital postoperative ward, without intensive or respiratory support, using cephalothin for six days. 


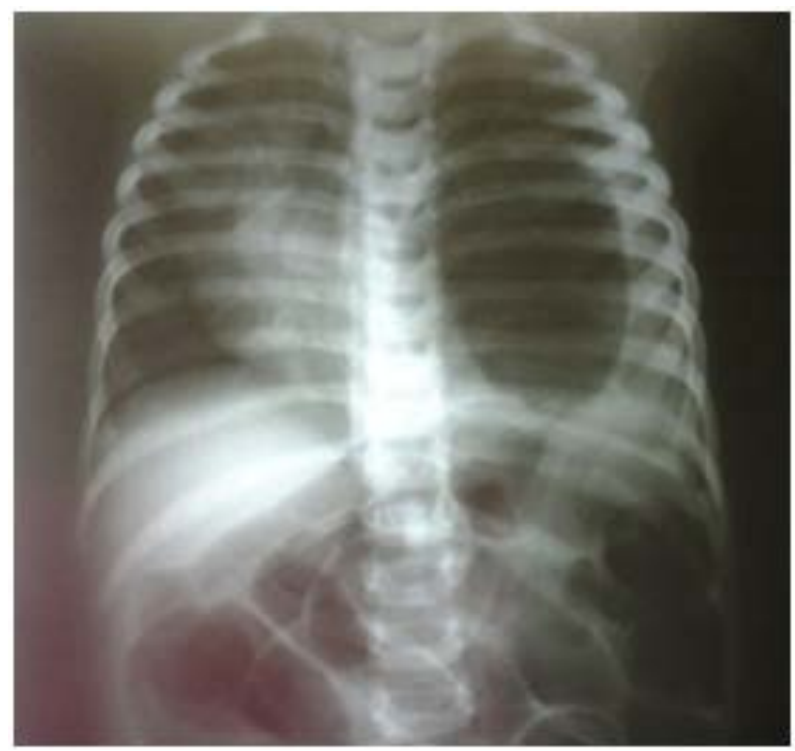

Figure 2. Thoracoabdominal $\mathrm{Rx}$ showing intestinal wall and part of the stomach in the left lung field.

Diet was started on the 3rd postoperative day with good acceptance.

Patient developed progressive clinical improvement and was discharged on the 6th day after surgery.

\section{Discussion}

Dom Malan Hospital in Petrolina-PE is the reference unit in maternal and child care in a region of 17 municipalities, and in the period from July 2012 to July 2013, there was total of 17,030 births in these municipalities [8].

Delayed presentation of $\mathrm{CDH}$ is an uncommon finding, the incidence ranging from $5 \%$ to $30 \%$ [3] cases of diaphragmatic hernia.

In the present study, 2 cases of delayed diagnosis were observed, indicating the possibility of subdiagnosis, which may result from lack of resources and failure in prenatal diagnosis.

Delayed diagnosis of these two patients with initial hypothesis of pneumonia, no previous reports of respiratory infection or dyspnea, demonstrates high risk and exposure of these children when the diagnosis does not happen in the prenatal period.

The CDH can be diagnosed prenatally by ultra-sound, which remains as a screening method for its availability, relatively low cost and the safety of the test. However, ultrasonography still presents a diagnostic failure rate of $41 \%$ cases of diaphragmatic hernia, and not following the protocols, as no documentation of the stomach location and heart position in the chest are the most common reasons, corresponding to $57 \%$ of cases and the examiner's failure, which is responsible for $33 \%$ diagnosis errors [9].

When the diagnosis is not established in the prenatal or neonatal period, the clinical presentation may vary from respiratory events (respiratory distress, cough, upper respiratory tract infection, pneumonia) in $43 \%$ of cases, gastrointestinal symptoms (vomiting, bloating and abdominal pain, constipation) in 33\% of cases, and patients present respiratory and gastrointestinal events concurrently (13\%) or even if present asymptomatically (11\%) [2] [10].

The prognosis in cases of $\mathrm{CDH}$ delayed diagnosis is generally very good, when the diagnosis is made correctly, but it is important to remember that these may reflect the milder cases not diagnosed in the neonatal period, despite more severe cases presenting pulmonary hypoplasia and persistent pulmonary hypertension, which are mainly responsible for the still high mortality of this disease [1].

It is essential to emphasize the diagnostic difficulties faced by the doctor when dealing with late cases of $\mathrm{CDH}$ due to its rarity and diverse clinical presentation, often mistaken for other diseases of the respiratory tract and wrongly treated as such.

Thus, the importance of observation of the clinical evolution should be emphasized, in addition to the correct 
interpretation of imaging studies and consideration of the disease in all age groups when the event is raised.

Through this study and the cases reported here, the need for early diagnosis can be reaffirmed, preferably in the prenatal period, in view of the potential complications of this disease if this diagnosis does not occur.

The diagnostic keys are clinical suspicion and carrying out chest radiography. However, the variety of organs and the size of the hernia defect can turn the radiographic interpretation in an extremely difficult task.

In addition, the hernia may present intermittently and the presence of a normal chest radiograph does not exclude the diagnosis [3].

It is recommended to always remember this as a differential diagnosis in different clinical situations that arise with any of the signs and symptoms of $\mathrm{CDH}$. This is the only way for the diagnosis of this pathology index may increase, often confused with pneumonia, tumor or other respiratory diseases, as occurred in the cases reported here.

Through this study, the need for research of this diagnosis in the neonatal period is reaffirmed, as a differential in different clinical situations that arise with any of the signs and symptoms of $\mathrm{CDH}$.

\section{Conclusion}

Congenital diaphragmatic hernia is an uncommon disease, and the early diagnosis will avoid the risks of potential complications. This condition must be reminded as a differential diagnosis in clinical situations which presents signs and symptoms compatible with HDC, not only in the neonatal period, but also in other age groups.

\section{Conflicts of Interests}

This research does not present any conflicts of interests.

\section{Auxiliary Supply}

There was no funding agency or supplier or any kind of aid received.

\section{References}

[1] Mielniczuk, M., Kusza, K., Brzeziński, P., Jakubczyk, M., Mielniczuk, K. and Czerwionka-Szaflarska, M. (2012) Current Management of Congenital DiaphragmaticHernia. Anaesthesiology Intensive Therapy, 44, $232-237$.

[2] Santos, E. and Ribeiro, S. (2008) Hérnia Diafragmática Congénita—artigo de revisão Congenital Diaphragmatic Hernia-A Review. Acta Obstet Ginecol Port, 2, 25-33.

[3] Yap, K.H. and Jones, M. (2013) Late Presentation of Congenital Diaphragmatic Hernia after a Diagnostic Laparoscopic Surgery (a Case Report). Journal of Cardiothoracic Surgery, 8, 8. http://dx.doi.org/10.1186/1749-8090-8-8

[4] Kotecha, S., Barbato, A., Bush, A., Claus, F., Davenport, M., Delacourt, C., Deprest, J., Eber, E., Frenckner, B., Greenough, A., Nicholson, A.G., Antón-Pacheco, J.L. and Midulla, F. (2012) Congenital Diaphragmatic Hernia. European Respiratory Journal, 39, 820-829. http://dx.doi.org/10.1183/09031936.00066511

[5] Tsao, K. and Lally, K.P. (2012) Innovations in the Surgical Management of Congenital Diaphragmatic Hernia. Clinics in Perinatology, 39, 363-374. http://dx.doi.org/10.1016/j.clp.2012.04.002

[6] Michel, F., Baumstarck, K., Gosselin, A., Le Coz, P., Merrot, T., Hassid, S., Chaumoître, K., Berbis, J., Martin, C. and Auquier, P. (2013) Health-Related Quality of Life and Its Determinants in Children with a Congenital Diaphragmatic Hernia. Orphanet Journal of Rare Diseases, 8, 89. http://dx.doi.org/10.1186/1750-1172-8-89

[7] Partridge, E.A., Bridge, C., Donaher, J.G., Herkert, L.M., Grill, E., Danzer, E., Gerdes, M., Hoffman, C.H., D’Agostino, J.A., Bernbaum, J.C., Rintoul, N.E., Peranteau, W.H., Flake, A.W., Adzick, N.S. and Hedrick, H.L. (2014) Incidence and Factors Associated with Sensorineural and Conductive Hearing Loss among Survivors of Congenital Diaphragmatic Hernia. Journal of Pediatric Surgery, 49, 890-894. http://dx.doi.org/10.1016/j.jpedsurg.2014.01.019

[8] Departamento de Informática do Sistema Único de Saúde (Datasus), Ministério da Saúde (MS), Brasil (2014) Informações de Saúde. Nascidos vivos.

http://www2.datasus.gov.br/DATASUS/index.php?area=0205\&VObj=http://tabnet.datasus.gov.br/cgi/deftohtm.exe?si nasc/cnv/nv

[9] Leitzke, L., Osório, C.M. and Moretti, G.F. (2007) Diagnóstico Pré-natal de Hérnia Diafragmática Congênita por Imagem de Ressonância Magnética. ACM Arquivos Catarinenses de Medicina, 36.

[10] Kesieme, E.B. and Kesieme, C.N. (2011) Congenital Diaphragmatic Hernia: Review of Current Concept in Surgical Management. ISRN Surgery, 2011, 8 p. http://www.hindawi.com/journals/isrn/2011/974041/cta/ 